\title{
Parkinson's Disease and Sexual Dysfunctions in Men
}

\author{
Ghulam Nabi ${ }^{1, *}$, Muhammad Amin ${ }^{2}$, Yousaf Khan ${ }^{3}$, Azam Khan ${ }^{4}$ \\ ${ }^{1}$ Department of Animal Sciences, Reproductive neuro endocrinology Lab; Quaid-i-Azam University, Islamabad, 45320, Pakistan \\ ${ }^{2}$ Department of Zoology, University of Karachi, 75270, Pakistan \\ ${ }^{3} \mathrm{Zia}$ Udin medical University, Karachi, Pakistan \\ ${ }^{4}$ Department of Biotechnology, University of Malakand, Pakistan \\ *Corresponding Author: ghulamnabiqau@gmail.com
}

Copyright (C) 2014 Horizon Research Publishing All rights reserved

\begin{abstract}
The objectives of this study were to analyze the difference between morning serum total testosterone level, cortisol level and sexual health status in Parkinson's patients and age matched control group. A standard questionnaire was designed regarding their socio-economic status, clinical records and sexual health. $5 \mathrm{~mL}$ of the blood samples were taken from all the participants and were analyzed for serum total testosterone and cortisol using Bio-check (USA) and GmbH (Germany) test kit. In Parkinson's patients serum cortisol level was significantly higher $\left(\right.$ Mean $\pm \mathrm{SEM}=326.6 \pm 6.34 \mathrm{mU} / \mathrm{L}, P^{* * * *}<0.0001$ ) as compared to control group (Mean $\pm \mathrm{SEM}=249.4 \pm 7.64$ $\mathrm{mU} / \mathrm{L}$ ). Serum total testosterone level in Parkinson's patients was significantly lowered (Mean $\pm \mathrm{SEM}=450.6 \pm 5.40 \mathrm{ng} / \mathrm{dl}$, $P^{* * * *}<0.0001$ ) as compared to control group (Mean \pm SEM $=534.3 \pm 6.31 \mathrm{ng} / \mathrm{dl}$ ). Sexual health problems like, erectile dysfunction, difficulties in ejaculation, decreased libido, dissatisfaction with sexual life, difficulties in reaching orgasm, absent morning and nocturnal erection and stopped having sex were common in Parkinson patients as compared to age matched control group. Parkinson disease negatively affects sexual health by reducing serum total testosterone and increasing serum cortisol level.
\end{abstract}

Keywords Parkinson, Testosterone, Cortisol

\section{Introduction}

Sexual dysfunction (SD) is very common in Parkinson's patient and in patients with other neurological disorders [1,2]. $\mathrm{SD}$ is the most common distressing and disabling characteristics of Parkinson's disease [1,3]. In PD patient depression is very common. PD affects arousal, reduces sexual satisfaction and sexual function [4,5]. In PD there is difficulty in fine finger movement, immobility in bed, rigidity and tremors. All these negatively affect the heartfelt touching needed for sexual arousal and sexual satisfaction. PD patients look less attractive

Because of gait disturbances, high sweating, drooling and altered physical appearance. Masked faces indicate less or no sexual desire. PD patients are sexually passive because of bradykinesia and rigidity. Insomnia is very common in PD patients, leading to bed separation and so negatively affecting the close contact [3,6]. In PD patient's testosterone deficiency is very common when compared with age-matched control subjects [7]. Decrease level of serum testosterone leads to depression, reduced nocturnal and morning erection, low libido, decreased frequency for shaving and erectile dysfunctions [8]. Insomnia in PD patients causes stressful condition in the body. This stress increases the level of serum cortisol. Serum cortisol negatively affects the secretion of serum testosterone indirectly by decreasing the expression of kisspeptin neurons of arcuate nuclei (ARC) and increasing the expression of RF-amide related peptide 3 (RFRP-3) [9,10].

The main objectives of this study were to analyze the status of sexual health in Parkinson's patients and age matched control group by measuring serum total testosterone levels, cortisol levels and investigating sexual problems in men. Only those PD patients were recruited in the study which were either not taking medicine totally or regularly due to, ignorance by their family members, boredom from medications, poverty, non-availability of medicine, terrorism etc. A standard questionnaire was designed regarding their socio-economic, general and sexual health.

\section{Materials and Methods}

\subsection{Inform Consent}

A written informed consent was signed from all the participants. They were informed about the purpose of study and were assured that their information will be strictly used for research work.

\subsection{Study Area}

The participants were recruited from district Dir (Lower) and Malakand agency, Khyber Pakhtunkhwa, Pakistan. 


\subsection{Study Design}

Two groups were made; control and PD. Control group participants were healthy. They were free from addiction, chronic illness and were not using any medications. Each group had 35 participants. Their age ranges from 45 to 55 years. A questionnaire regarding their socio-economic status, clinical records and sexual health were filled from all the participants in a separate room and stress proof environment.

\subsection{Blood Sampling}

Approximately $5 \mathrm{~mL}$ of the blood sample was taken by a medical technologist from the brachial vein of all participants aseptically. Vacutainer tubes containing no additives were used for blood collection. This blood sampling was made at 9:00 $\mathrm{AM}$ to 10:00 $\mathrm{AM}$ after breakfast. The blood samples were allowed to clot at room temperature and then centrifuged at $3200 \mathrm{rpm}$ for 15 minutes at $4 \mathrm{C}^{0}$. The serums obtained were then stored at $-20^{\circ} \mathrm{C}$ for assays.

\subsection{Assays}

For total serum testosterone, Bio-check (USA) and for cortisol, GmbH (Germany) test kit was used according to the manufacturer protocol and instructions.

\subsection{Inclusion Criteria}

Diagnosed Parkinson patients, married men having their spouses, same age range, same economic status, same profession and free from chronic illness.

\subsection{Statistics}

The software Graph Pad Prism, version 6.03 (Graph Pad Software Inc., San Diego, CA, USA) was used for data analysis. To compare the values of both groups student un-paired $t$ test was used. Results obtained were represented through Mean \pm SEM. A value of $p<0.05$ was considered statistically significant.

\section{Results}

\subsection{History}

The histories of both groups are summarized in Table 1 .

Table 1. History of study population

\begin{tabular}{|c|c|c|c|c|c|c|}
\hline $\begin{array}{c}\text { Group } \\
\text { Age range } \\
\text { Number }(n=)\end{array}$ & $\begin{array}{c}\text { Economic } \\
\text { status }\end{array}$ & profession & Medications & Addiction & Sleep & $\begin{array}{c}\text { Sexual } \\
\text { problems }\end{array}$ \\
\hline $\begin{array}{c}\text { Control } \\
45-55 \\
(\mathrm{n}=35)\end{array}$ & Poor & Farmers & Nill & & $\geq 8 \mathrm{hrs}$. & Absent \\
\hline $\begin{array}{c}\text { Parkinson } \\
45-55 \\
(\mathrm{n}=35)\end{array}$ & Poor & Farmers & L-dopa (14) & 4 Snuff & $<4$ hrs. & $\begin{array}{c}14 \mathrm{ED}^{*} \\
13 \mathrm{DSL}^{*} \\
08 \mathrm{DRO}^{*} \\
07 \mathrm{DL}^{*} \\
06 \mathrm{AMN}^{*} \\
04 \mathrm{SS}^{*} \\
03 \mathrm{DE}^{*}\end{array}$ \\
\hline
\end{tabular}

$\mathrm{ED}^{*}=$ Erectile dysfunction, $\mathrm{DE}^{*}=$ difficulties ejaculating, $\mathrm{DL}^{*}=$ decrease libido, $\mathrm{DSL}^{*}=$ Dissatisfaction with sexual Life, $\mathrm{DRO}^{*}=$ difficulties reaching orgasm, $\mathrm{AMN}^{*}=$ absent morning and nocturnal erection, $\mathrm{SS}^{*}=$ stopped having sex

\subsection{Total Serum Testosterone and Cortisol Concentration in Study Population}

The results showed that total serum testosterone is significantly reduced $\left(P^{* * * *}<0.0001\right)$ but serum cortisol is significantly increased $\left(P^{* * * *}<0.0001\right)$ in Parkinson patients when compared with control group. Details of the results are summarized in Table 2 .

Table 2. Hormonal profile of study population

\begin{tabular}{ccccc}
\hline Parameters & $\begin{array}{c}\text { Control } \\
\text { Mean } \pm \text { SEM }\end{array}$ & $\begin{array}{c}\text { Parkinson } \\
\text { Mean } \pm \text { SEM }\end{array}$ & $95 \%$ C.I* & $P$ value \\
\hline Total serum testosterone & $\begin{array}{c}534.3 \pm 6.31 \\
(\mathrm{ng} / \mathrm{dl})\end{array}$ & $\begin{array}{c}450.6 \pm 5.40 \\
(\mathrm{ng} / \mathrm{dl})\end{array}$ & -100 to -67.18 & $P^{* * * *}<0.0001$ \\
Serum cortisol & $\begin{array}{c}249.4 \pm 7.64 \\
(\mathrm{mU} / \mathrm{L})\end{array}$ & $\begin{array}{c}326.6 \pm 6.34 \\
(\mathrm{mU} / \mathrm{L})\end{array}$ & 57.46 to 97.0 & $P^{* * * *}<0.0001$ \\
\hline
\end{tabular}

$\mathrm{CI}^{*}=$ confidence intervals 


\section{Discussion}

Kisspeptin is a neuro-hormone. It is mainly synthesized in the ARC nuclei of hypothalamus. Kisspeptin acts on gonadotropin releasing hormone $(\mathrm{GnRH})$ neuron through G-protein couple receptor and releases $\mathrm{GnRH}$ into the median eminence. GnRH has receptors on anterior pituitary (gonadotrops) and causes the release of Luteinizing hormone (LH) and follicle stimulating hormone (FSH). LH is then responsible for the synthesis of testosterone in leydig cells of testes [11]. Similarly RFRP-3 (also called gonadotropin inhibitory hormone) inhibits gonadotropin Synthesis and secretion [12].

Insomnia in PD patients creates a state of stress in the body. This stress produces negative effects on the hypothalamic-pituitary-gonadal (HPG) axis at several levels. Centrally it stimulates hypothalamic-pituitary-adrenal (HPA) axis $[13,14]$. The hypothalamus in response to stress secretes corticotrophin releasing hormone (CRH) into the hypophysial portal system. $\mathrm{CRH}$ has receptors in anterior pituitary which causes the release of adrenocorticotropic hormone (ACTH). This ACTH stimulates adrenal glands to secrete glucocorticoids (GCs) [15]. This increased level of GCs negatively affects the HPG-axis in two ways. On one hand it increases the expression of RFRP-3, leading to inhibition of gonadotropin synthesis and secretion [16]. But on the other hand, it decreases the expression of ARC kisspeptin neurons, resulting into less secretion of pulsatile kisspeptin hormone. As a result very less GnRH is released and thus suppresses HPG-axis [9]. This has been confirmed experimentally that, administration of RFRP-3 into male rats leads to inhibition of $\mathrm{LH}$ and suppression of sexual behavior, much as stress does [17].Similarly glucocorticoids administration inhibits circulating gonadotropin levels in rats [14], rhesus monkeys [15] and humans [18]. It also causes fewer implantation sites and live fetuses in female mates [19]. The effect of stress on plasma LH was blocked by using CRH receptor antagonists $[14,20]$. Similarly adrenalectomy inhibits the stress induced increase in RFRP-3 expression, suggesting that RFRP-3 alteration depends on elevated GCs [16]. In adult men stress has been linked to infertility [21], medical students are associated with lower sperm motility [22] and lower proceptive sexual behavior [23].

Cortisol disturbs sleep and promotes wakefulness. It also increases EEG frequency which is associated with increased wakefulness and/or shallower sleep stage [24]. It has been found that fathers who sleep with their children, have low morning testosterone as compared to control group because of disturbed sleep [25]. Bus drivers are exposed to sleep deprivation. They if sleep in buses, have disturbed sleep, so all stages of sleep especially REM stage is not achieved properly. As a result their morning serum total testosterone is lowered as compared to control group [26]. Men who sleep for less than $4 \mathrm{hrs}$ have significantly lower testosterone as compared to men who slept for over 8 hours [27]. Short REM and fragmented sleep causes a significant reduction in serum total testosterone, leading to diminished libido, ejaculatory problems and erectile dysfunctions [28,29].

Apart from $\mathrm{GnRH}$, dopamine has a role in promoting copulatory proficiency, genital reflex and sexual motivation. Before and during mating dopamine is released and facilitates copulation [30,31]. In PD patients erectile dysfunction, internalizing tremor during arousal and difficulty in reaching orgasm are common [32]. Erectile dysfunction occurs two fold high in PD patients. They were also less satisfied with their partners and sexual relationship and were more depressed as compared to age match control group [33,34]. The prevalence of SD in male PD patients were found to be high $(65 \%)$ as compared to female PD patients (36\%) [35].In a study sexual functions were analyzed in 75 PD patients. It was found that $68 \%$ of men reported erectile dysfunctions, $65 \%$ sexual dissatisfactions, $41 \%$ premature ejaculation and $40 \%$ reported difficulties in reaching an orgasm [36]. In $90 \mathrm{PD}$ patients both quality of life and quality of sexual life were assessed through questionnaires. They found that in all PD patients, quality of sexual life was significantly reduced and that it worsened with the progression of disease and aging [2].

\section{Conclusions}

In summary, PD patients are sleep deprived. They are in a state of continuous stress. Persistent stress for a long time raises serum cortisol level. High cortisol level decreases serum total testosterone level by decreasing the pulsatility of kisspeptin. Low serum testosterone level leads to erectile dysfunction, difficulties in ejaculation, decreased libido, dissatisfaction with sexual life, difficulties in reaching orgasm, absent morning and nocturnal erection and stopped having sex. Further studies are needed to investigate the effects of kisspeptin administration in PD patients.

\section{REFERENCES}

[1] EM. Frohman. Sexual dysfunction in neurologic disease. Clin Neuropharmacol, 25,126-132, 2002.

[2] O. Moore, T. Gurevitch, AD. Korczyn, M. Anca, N. Giladi. Quality of sexual life in Parkinson's disease. Parkisnsonism Relat Disord, 8,243-246,2002.

[3] WC. Koller, B. Vetere-Overfield, A. Williamson, K. Busenbark, J. Nash, D. Parrish. Sexual dysfunction in Parkinson's disease. Clin Neuropharmacol,13,461-463,1985.

[4] H. Jacobs, A. Vieregge, P. Vieregge. Sexuality in young patients with Parkinson's disease: A population based comparison with healthy controls. J Neurol Neurosurg Psychiatry,69, 550-552,2000.

[5] H. Lipe, WT. Longstreth, TD. Bird, M. Linde. Sexual function in married men with Parkinson's disease compared to married men with arthritis. Neurology, 40,1347-1349, 1990. 
[6] R. Basson. Sex and idiopathic Parkinson's disease. Parkinson's disease. Advances in Neurology,86, 295-300, 2001 .

[7] MS. Okun, WM. McDonald, MR. DeLong. Refractory nonmotor symptoms in male patients with Parkinson disease due to testosterone deficiency: a common unrecognized comorbidity. Arch Neurol,59,807-811, 2002.

[8] J. Buvat, M. Maggi, A. Guay, L. Torres. Testosterone deficiency in men: Systematic review and standard operating procedures for diagnosis and treatment. J Sex Med, 10, 245284, 2013.

[9] ED. Kirby, AC. Geraghty, T. Ubuka, GE. Bentley, D. Kaufer. Stress increases putative gonadotropin inhibitory hormone and decreases luteinizing hormone in male rats. Proc Natl Acad Sci USA, 106, 11324-11329,2009.

[10] DC. Cumming, ME. Quigley, SS. Yen. Acute suppression of circulating testosterone levels by cortisol in men. J Clin Endocrinol Metab,57,671-3, 1983.

[11] WS. Dhillo, OB. Chaudhri, EL. Thompson. Kisspeptin-54 stimulates gonadotropin release most potently during the preovulatory phase of the menstrual cycle in women. J Clin Endocrinol Metab,92, 3958-66, 2007.

[12] K. Tsutsui, E. Saiqoh, K. Ukena, H. Teranishi, Y. Fujisawa, M. Kikuchi. A novel avian hypothalamic peptide inhibiting gonadotropin release. Biochem Biophys Res Commun,275,661-667,2000.

[13] C. Rivier, S. Rivest. Effects of stress on the activity of the hypothalamic-pituitary-gonadal axis: peripheral and central mechanisms. Biol Reprod, 45, 523-32,1991.

[14] C. Rivier, J. Rivier, W. Vale. Stress-induced inhibition of reproductive functions: Role of endogenous corticotropin-releasingfactor.Science,231,607-609,1986.

[15] AK. Dubey, TM. Plant. A suppression of gonadotropin secretion by cortisol in castrated male rhesus monkeys (Macaca mulatta) mediated by the interruption of hypothalamic gonadotropin-releasing hormone release. Biol Reprod,33,423-431,1985.

[16] DK. Elizabeth, CG. Anna, U. Takaushi. stress increases putative gonadotropin inhibitory hormone and decreases luteinizing hormone in male rats. Neurosciences, 106,11324-11329,2009.

[17] MA. Johnson, K. Tsutsui, GS. Fraley. Rat RFamide-related peptide-3 stimulates GH secretion, inhibits LH secretion, and has variable effects on sex behavior in the adult male rat. Horm Behav,51,171-180,2007.

[18] M. Sakakura, K. Takebe, S. Nakagawa. Inhibition of luteinizing hormone secretion induced by synthetic LRH by long-term treatment with glucocorticoids in human subjects. J Clin Endocrinol Metab,40,774-779,1975.

[19] SA. Lerman, GK. Miller, K. Bohlman, V. Albaladejo, JF. Leonard, V. Devas. Effects of corticosterone on reproduction in male Sprague- Dawely rats. Reprod Toxicol,11,799-805,1997.

[20] XF. Li, JE. Bowe, JS. Kinsey-jones, SD. Brain. SL. Lightman. Differential role of corticotropin-releasing factor receptor types 1 and 2 in stress-induced suppression of pulsatile luteinizing hormone secretion in female rat. J Neuroendocrinol, $18,602-610,2006$.

[21] EK. Sheiner, E. Sheiner, R. Carel, G. Potashnik, I. Shoham-Vardi. Potential association between male infertility and occupational psychological stress.J Occup Environ Med, 44,1093-1099,2002.

[22] S. Eskiocak, AS. Gozen, SB. Yapar, F. Tavas, AS. Killic. Glutathione and free sulphydryl content of seminal plasma in healthy medical students during and after exam stress. Hum Reprod,20,2595-2600, 2005.

[23] Y. Sato, N. Suzuki, H. Horita, H. Wada, A. Shibuya, H. Adachi. Effects of long-term psychological stress on sexual behavior and brain catecholamine levels. J Androl, 17,8390,1996

[24] A. Miyatake, Y. Morimoto, T. Oishi. Circadian rhythm of serum testosterone and its relation to sleep: comparison with the variation in serum luteinizing hormone, prolactin, and cortisol in normal men. J Clin Endocrinol Metab,51,136571,1980

[25] LT. Gettler. Does Cosleeping Contribute to Lower Testosterone Levels in Fathers? Evidence from the Philippines. Plos one, 7, 41559,2012.

[26] N. Ghulam, A. Muhammad, U. Rahim, K. Amjad, S. Muhammad, AK. Ayaz. The effects of long term sleep and exercise deprivation on total serum testosterone in male professional drivers. JBLS,5, 48-57,2014.

[27] A. Monica. A. Tathiana, M. Renata, H. Helena, T. Sergio. The association of Testosterone, sleep, and sexual function in men and women. Brain Res,1416, 80-104,2011.

[28] LA. Monica, SS. Rogerio, RA. Lia, ST. Bittencourt. Prevalence of erectile dysfunction complaints associated with sleep disturbances in Sao Paulo, Brazil: A population-based survey. Sleep Medicine,11,1019-1024,2010.

[29] P. Penev. Association between sleep and morning testosterone levels in older men. Sleep,30, 427-432,2007.

[30] JM. Dominguez, EM. Hull. Dopamine, the medial preoptic area, and male sexual behaviour. Physiol Behav,26,1699-703,2005.

[31] EM. Hull, JM. Dominguez. Getting his act together: roles of glutamate, nitric oxide, and dopamine in the medial preoptic area. Brain Res, 1126, 66-75,2006.

[32] R. Basson. Sexuality and Parkinson's disease. Parkinsonism Relat disord,2,177-85,1996.

[33] M. Welsh, L. Hung, CH. Waters. Sexuality in women with Parkinson's disease. Mov Disord,12, 923-7,1997.

[34] P. Hobson, W. Islam, S. Roberts, V. Adhiyman, J. Meara. The risk of bladder and autonomic dysfunction in a community cohort of Parkinson's disease patients and normal control. Parkinsonism Relat disord,10,67-71,2003.

[35] RG. Brown, M. Jahanshahi, N. Quinn, CD. Marsden. Sexual function in patients with Parkinson's disease and their partners. J Neurol Neurosurg Psychiatry,53,480-6,1990

[36] G. Bronner, V. Royter, AD. Korczyn. N. Giladi. Sexual dysfunction in Parkinson's disease. J Sex Marital Ther Mare,30,95-105,2004 